\title{
ESTADO DE ALARMA SANITARIA Y MEDIDAS LIMITATIVAS DE LA ACTIVIDAD ECONÓMICA ${ }^{1}$
}

\author{
Pablo Guerrero Vázquez \\ Profesor Ayudante Doctor de Derecho Constitucional, \\ Universidad de Zaragoza
}

Cómo citar este artículo / Citation: Guerrero Vázquez, P. (2021). Estado de alarma sanitaria y medidas limitativas de la actividad económica. Garrido López, C. (coord.) Excepcionalidad y derecho: el Estado de Alarma en España, Colección Obras colectivas, Fundación Manuel Giménez Abad, Zaragoza.

DOI: https://doi.org/10.47919/FMGA.OC21.0012

SUMARIO: I. INTRODUCCIÓN. II. DERECHO DE EXCEPCIÓN Y MEDIDAS LIMITATIVAS DE LA ACTIVIDAD ECONÓMICA: 1. Cierre empresarial y estado de alarma. 2. La intervención de empresas privadas y la requisa de bienes como medida para afrontar la crisis sanitaria. 3. Otras medidas limitadoras de la actividad económica: la normalidad en la excepción. A) Límites al legislador ordinario y libertad de empresa. B) Poder autonómico y restricciones a la libertad de empresa. III. INDEMNIZACIÓN POR LOS PERJUCIOS SUFRIDOS EN LA ESFERA PATRIMONIAL DE LOS PARTICULARES: 1. Un camino difícil de transitar: la posible responsabilidad patrimonial: 2. La expropiación como instrumento para intervenir empresas y requisar bienes.

\footnotetext{
${ }^{1}$ Este trabajo se enmarca en el desarrollo del proyecto de investigación (PID2019-104414GBC31), "El control y la responsabilidad política en el Estado constitucional con especial referencia al Parlamento en el contexto multinivel", financiado por el Ministerio de Economía y Competitividad.
} 


\section{INTRODUCCIÓN}

Los poderes públicos, con la finalidad de superar la emergencia sanitaria desencadenada en marzo de 2020, han adoptado durante los últimos meses innumerables medidas que han tenido una repercusión directa en la actividad económica. Bien sea bajo el paraguas del Derecho Constitucional de excepción, entre marzo y junio (RD 463/2020, de 14 de marzo), y también a partir de octubre (RD 926/2020, de 25 de octubre), o bien durante los meses de verano en la conocida como nueva normalidad.

Este trabajo centra sus esfuerzos en el estudio de aquellas medidas adoptadas durante la vigencia del Derecho Constitucional de excepción, aunque a lo largo del relato quedará puesto de manifiesto que algunas de ellas, aunque no todas, también eran susceptibles de ser implementadas al margen de este paraguas normativo. En efecto, durante estos meses no han sido pocas las medidas con una repercusión directa en la actividad económica -y en el derecho fundamental a la libertad de empresa- que, pese a haber sido acordadas estando vigente el Derecho de excepción, no fueron implementadas bajo el régimen jurídico previsto en el artículo 116 CE.

Muy posiblemente, de entre todas ellas, aquella medida que ha tenido una mayor notoriedad ha sido el cierre generalizado de buena parte del comercio minorista durante la vigencia del primer estado de alarma. Una medida, esta sí, que, por dirigirse a un colectivo indeterminado de destinatarios, fue acordada al amparo del Derecho de excepción. En el estado de alarma declarado en el otoño de 2020, por el contrario, no fue acordado directamente el cierre empresarial. Si bien, se impidió indirectamente la apertura de algunos sectores, como el ocio nocturno, al restringirse la movilidad de los ciudadanos durante aquella horquilla horaria en la que se desarrolla fundamentalmente esta actividad. Igualmente, se dificultó con severidad el desempeño de otras actividades, como todas las vinculadas con el sector turístico, al constreñirse la movilidad de los españoles entre Comunidades Autónomas, provincias e, incluso, entre municipios. Al estudio de todas estas cuestiones se dedica el primer subepígrafe del apartado II.

A continuación, el trabajo se detiene en otras medidas limitadoras de la libertad de empresa de naturaleza híbrida, por ser propias del Derecho de la excepción, pero, también, del de la normalidad. Es el caso de la posibilidad que asiste al sector público, en un contexto de emergencia, para intervenir empresas 
privadas y realizar requisas de bienes. En este marco se hará referencia, especialmente, a la posible intervención de hospitales privados ante la presión asistencial sufrida por la sanidad pública -una posibilidad jurídicamente viable, aunque solo parcialmente explotada durante la segunda ola de la pandemia-. No obstante, junto a esta medida, en un contexto de crisis sanitaria como el atravesado, se han adoptado otras decisiones que comprometen con una intensidad similar la extensión del derecho a la libertad de empresa -v. gr. concentración de residentes con un test de diagnóstico negativo en centros de titularidad privada-.

El epígrafe II concluye con el estudio de aquellas medidas que, pese a contar también con una repercusión indudable en la actividad económica, su adopción no está contemplada en el Derecho de excepción. Y, por ello, fueron acordadas bajo el marco jurídico propio de la normalidad, bien durante la vigencia de alguno de los dos estados de alarma declarados, o bien durante el oxímoron que supuso la conocida como nueva normalidad. Consecuentemente, en este apartado se aborda, en primer lugar, el espacio que constitucionalmente corresponde al legislador, ordinario o de urgencia, para delimitar el derecho a la libertad de empresa. $\mathrm{Y}$, posteriormente, el trabajo se detiene en las medidas limitadoras de la actividad económica adoptadas por los poderes autonómicos, ya que el régimen de distribución de competencias entre centro y periferia ha sido sustancialmente el propio de la normalidad desde el mes de junio.

En último lugar, aunque no por ello menos importante -sino todo lo contrario, pues es el colofón a todo cuanto se expondrá-, hay que tener en consideración que las medidas limitadoras de la actividad económica adoptadas durante la presente crisis sanitaria, han tenido un severo impacto en la cuenta de resultados de buena parte de los sectores. $Y$ muy especialmente, como se apuntaba, en algunos de ellos, como la hostelería y el ocio nocturno. Por ello, para concluir (epígrafe III), este capítulo se aproxima a las posibilidades que asisten a los sujetos perjudicados por estas decisiones para revertir, o paliar, los perjuicios económicos padecidos durante la crisis sanitaria desencadenada por la pandemia de la covid-19. 


\section{DERECHO DE EXCEPCIÓN Y MEDIDAS LIMITATIVAS DE LA ACTIVIDAD ECONÓMICA}

El 14 de marzo de 2020, no hay quien no lo recuerde, en un contexto de emergencia sanitaria, fue activado en España el Derecho Constitucional de excepción. Por Real Decreto 463/2020, de 14 de marzo, se declaró el estado de alarma en la totalidad del territorio nacional, que estaría en vigor hasta el 21 de junio de aquel año. Unos meses después, atendiendo a la preocupante evolución de la situación epidemiológica, el Gobierno de España se vio abocado a activar de nuevo el Derecho Constitucional de excepción, y declaró un nuevo estado de alarma por Real Decreto 926/2020, de 25 de octubre -vigente todavía en el momento de redactarse estas líneas y que se prolongará, previsiblemente, al menos hasta mayo de 2021 -

Es incuestionable, y no merece la pena detenernos ahora a justificarlo, que tanto en marzo como en octubre concurría uno de los supuestos de hecho que permiten la declaración del estado de alarma. En efecto, el artículo 4 b) de la Ley Orgánica 4/1981, de 1 de junio, de los estados de alarma, excepción y sitio (LOAES), faculta al Gobierno de España para declarar el estado de alarma en situaciones críticas desde un punto de vista sanitario, tales como una epidemia, según ejemplifica expresamente dicha disposición. Por ello, la controversia jurídica, y en consecuencia el debate académico, apenas ha girado en torno a la corrección jurídico-constitucional del supuesto de hecho, sino que el mismo ha versado principalmente sobre las medidas adoptadas por el Gobierno una vez declarada la excepción. Es decir, sobre las consecuencias jurídicas asociadas a la declaración de la excepcionalidad. A su análisis se dedican las siguientes líneas.

\section{Cierre empresarial y estado de alarma}

El artículo 10 del Real Decreto 463/2020, de 14 de marzo, contemplaba expresamente la suspensión temporal de la apertura al público -es decir, el cierre- de los locales y establecimientos minoristas, con una serie de excepciones. El cierre temporal acordado en marzo fue una decisión generalizada e indiscriminada, pues no cabía continuar desarrollando la actividad comercial, ni aun cuando un establecimiento garantizase la observancia una serie de medidas higiénico sanitarias-. Y, por ello, hubo quien 
consideró que esta decisión provocaba la suspensión del derecho a la libertad de empresa reconocido en el artículo 38 CE. Máxime cuando la suspensión temporal de la actividad ha devenido en definitiva en muchas ocasiones. No se puede olvidar, en todo caso, que el Tribunal Constitucional ha reconocido que la facultad de iniciar y mantener en el tiempo una actividad empresarial forma parte del contenido esencial de este derecho (STC 225/1993, de 8 de julio).

Con base en el citado artículo 10, tan solo se permitía la apertura de establecimientos destinados a la venta de productos de primera necesidad, clínicas veterinarias, prensa y papelería, combustible para la automoción, equipos tecnológicos... La primera redacción del RD 463/2020, elaborada presumiblemente de manera apresurada ante la magnitud de las circunstancias, provocó cierta confusión entre la ciudadanía, pues su artículo 7 limitaba de manera severísima su libertad ambulatoria, mientras que el artículo 10 permitía la apertura de algunos establecimientos pese a no estar meridianamente claro si cabía abandonar el domicilio para acudir a los mismos.

Hubo que esperar hasta la redacción dada al RD 463/2020 por RD 492/2020, de 24 de abril, para que el artículo 7, expresamente, autorizase los desplazamientos a los establecimientos cuya apertura no estaba suspendida. Desde un punto de vista práctico, esta discordancia entre la redacción de los artículos 7 y 10 RD 463/2020 no planteó problemas, pues se entendió desde un primer momento que cabía abandonar el domicilio para acudir a todos los establecimientos abiertos. Sin embargo, esta desavenencia entre ambos preceptos nos resulta muy ilustrativa, porque pone de relieve la estrecha relación que existe entre ellos.

En efecto, ambas disposiciones son las dos caras de la misma moneda, pues mientras el artículo 10 pretende dejar las calles sin atractivos, el artículo 7 las vacía directamente. Ambas medidas persiguen lo mismo -reducir la movilidad social y el contacto interpersonal-, pero por caminos diferentes -el artículo 10 de manera indirecta y, por el contrario, el 7 de manera inmediata-. El cierre comercial, en este sentido, no fue sino una garantía para reforzar el cumplimiento de las limitaciones a la movilidad personal introducidas en el artículo 7 RD 463/2020, que era la verdadera clave de bóveda del estado de alarma declarado en marzo.

Por ello, a la hora de analizar la corrección jurídico-constitucional del artículo 10 debemos de partir, creo, de su carácter instrumental. La suspensión de la 
actividad empresarial perseguía facilitar el control de la prohibición contemplada en el artículo 7, pues si el recurso a la picaresca para abandonar el domicilio fue más frecuente de lo deseable con el comercio cerrado, parece que hay que albergar pocas dudas sobre cuál habría sido el resultado del confinamiento domiciliario si hubiese sido lícita la entrada a la mayor parte de establecimientos abiertos al público ${ }^{2}$. Este es el contexto dentro del que debemos encuadrar el debate sobre la corrección en términos de constitucionalidad del artículo 10 RD 463/2020.

El artículo $116 \mathrm{CE}$ ha sido desarrollado por mandato constitucional por la LOAES y, por ello, esta última norma se convierte en canon para enjuiciar la constitucionalidad de aquellas otras, como el RD 463/2020, que activan el Derecho Constitucional de excepción y que, hoy ya no cabe duda (STC 83/2016, de 28 de abril), tienen asimismo rango de ley ${ }^{3}$.

Si el artículo 4 LOAES contempla el supuesto de hecho que permite la declaración del estado de alarma, los artículos 11 y 12 LOAES hacen lo propio con las consecuencias jurídicas asociadas a tal declaración. $Y$, entre ellas, y en lo que aquí interesa, destaca la posibilidad "de intervenir y ocupar transitoriamente industrias, fábricas, talleres, explotaciones o locales de cualquier naturaleza" (art. 11 c) LOAES). Sin embargo, como se ha apuntado, el artículo 10 RD 463/2020 no acordó propiamente la intervención de algunos locales comerciales, sino la suspensión temporal de su actividad. Una medida esta que solo está contemplada en el marco del estado de excepción (art. 26 LOAES).

En esta línea, se ha sostenido que la intervención y el cierre no son conceptos equivalentes, pues mientras la intervención simplemente limita el derecho a la libertad de empresa, la imposición del cierre comporta su suspensión. Y por ello, una medida de este cariz solo debería encontrar acomodo en el marco del estado de excepción, en el que sí que cabe la suspensión de derechos fundamentales (art. $55 \mathrm{CE}$ ).

\footnotetext{
${ }^{2}$ La suspensión de toda actividad no esencial, entre los días 30 de marzo y 9 de abril, como veremos, fue una decisión adoptada durante la vigencia del estado de alarma, pero al margen del régimen jurídico de la excepción. Razón por la cual la estudiamos en el tercer subepígrafe de este mismo apartado.

3 GARRIDO LÓPEZ, C., "Naturaleza jurídica y control jurisdiccional de las decisiones constitucionales de excepción", Revista Española de Derecho Constitucional, núm. 110, 2017, pp. 43-73.
} 
Por ello un sector doctrinal ${ }^{4}$, y también parte del arco parlamentario, dudó de la constitucionalidad del artículo 10 RD 463/2020, habiendo sido interpuesto contra el mismo un recurso de inconstitucionalidad que, hoy en día, continúa sub iudice ${ }^{5}$. Todo cuanto aquí se escriba, en consecuencia, queda a la espera de lo que falle el máximo intérprete de la Constitución. Si bien, esta situación de litispendencia no es óbice para tratar de profundizar sobre este particular.

Ciertamente, la suspensión temporal de la actividad empresarial está contemplada expresamente en el marco del estado de excepción, y no en el de alarma. Y solo bajo el primero de ellos, suele esgrimirse, cabe la suspensión de derechos fundamentales. Sin embargo, no podemos olvidar que el artículo 55 $\mathrm{CE}$, al determinar los derechos susceptibles de suspensión dentro del marco del estado de excepción, no hace referencia tampoco a la libertad de empresa, reconocida en el artículo $38 \mathrm{CE}$. Y no por ello ha sido cuestionada, al menos hasta la fecha, la constitucionalidad del artículo 26 LOAES.

En puridad, por lo tanto, tan inconstitucional sería el cierre de la actividad empresarial con base en el artículo 11 como en el artículo 26 LOAES. En el caso de que el cierre empresarial fuese acordado tras haber sido declarado el estado de alarma -tal y como ocurrió en marzo de 2020-, la decisión gubernamental tendría un acomodo discutible en la literalidad del artículo 11 LOAES. Por el contrario, si el cierre fuese decidido tras la declaración del estado de excepción, tal decisión encajaría con facilidad en la literalidad del artículo 26 LOAES, pero esta última disposición contaría con un anclaje constitucional muy débil.

¿Quiere ello decir que el titular del Derecho de excepción puede acordar, póngase por caso, el confinamiento generalizado de la población, pero no el cierre de un determinado sector empresarial? Una solución de este tenor no parece útil desde un punto de vista práctico, ni razonable desde uno jurídico, pues quien puede lo más, debe poder lo menos -a maiori ad minus-. El Derecho de excepción, que se activa cuando el principio de necesidad impera, cuenta con su propia lógica: salus populi suprema lex est. Y aunque la

\footnotetext{
${ }^{4}$ RUIZ MIGUEL, C., "Covid-19: ¿Está en riesgo el estado de Derecho?”, Cinco Días, 28 de abril de 2020.

${ }^{5}$ Los diputados del Grupo Parlamentario VOX en el Congreso de los Diputados interpusieron el 28 de abril de 2020 un recurso de inconstitucionalidad contra, entre otros, el artículo 10 RD 463/2020, por vulnerar los artículos 35 y 38 CE. Contenido disponible en línea: https://www.voxespana.es/wp-content/uploads/2020/04/recurso-inconstitucionalidad-estadoalarma-VOX.pdf [última consulta: enero 2021].
} 
Constitución Española, en su artículo 116, y la LOAES, hacen un esfuerzo notable para racionalizar el ejercicio de este Derecho, es inevitable que acontezcan emergencias no suficientemente regladas.

La finalidad del Derecho de excepción no es otra, como apuntó en tempranas fechas Pedro Cruz, que la "modificación transitoria del régimen constitucional" para garantizar su propia supervivencia ${ }^{6}$. A esta misma lógica, como ha señalado más recientemente el propio Cruz Villalón ${ }^{7}$ (2020), también responde otro precepto constitucional regulador de la emergencia, el artículo $155 \mathrm{CE}$. Ciertamente, como es sabido, esta disposición pretende hacer frente a emergencias eminentemente políticas y de naturaleza territorial, pero parece conveniente traerla a colación atendiendo a que el TC ha tenido ocasión de pronunciarse sobre su aplicación al caso concreto (SSTC 89/2019 y 90/2019, de 2 de julio).

En su reciente jurisprudencia, el TC ha establecido que la coerción estatal faculta al centro para adoptar todas aquellas medidas necesarias para reestablecer el orden constitucional (límite material), sin que puedan perpetuarse en el tiempo, convirtiendo la excepción en regla (límite temporal) ${ }^{8}$. La STC 89/2019 señala, asimismo, que la activación de este instrumento excepcional no puede comportar la limitación o excepción del "patrimonio común de los ciudadanos constituido por los derechos fundamentales" (FJ 4). Sin embargo, el TC, ut infra, terminó avalando la constitucionalidad de una medida que permitió al Gobierno de España disolver el Parlament y que comportó, a la postre (RD 946/2017, de 27 de octubre), la suspensión en la práctica del ius in officium de sus integrantes.

Es sabido que el artículo $55 \mathrm{CE}$, al regular la suspensión de los derechos y libertades, no hace referencia a la posible suspensión del artículo 23.2 CE. Tampoco, y en lo que aquí interesa, hace referencia alguna al artículo $38 \mathrm{CE}$. Pero también es cierto que la adopción de una medida del tenor de la aludida durante la crisis secesionista resultaba ineludible y, por ello, el TC primero $^{9}$, y el

\footnotetext{
${ }^{6}$ CRUZ VILLALÓN, P., "El nuevo Derecho de excepción", Revista Española de Derecho Constitucional, núm. 2, 1981, pp. 93-130.

${ }^{7}$ CRUZ VILLALÓN, P., "Experiencia y jurisprudencia de la coerción estatal (artículo 155 CE)", Revista Española de Derecho Constitucional, núm. 120, 2020, pp. 15-41.

${ }^{8}$ REQUEJO PAGÉS, J. L., Consideraciones generales en torno a las sentencias del Tribunal Constitucional 89/2019 y 90/2019, de 2 de julio, Revista Española de Derecho Constitucional, núm. 120, pp. 231-257.

${ }^{9}$ GARCÍA ROCA, J., "Il tempo moderato de la intervención coercitiva del Estado (artículo155 CE) en Cataluña: un comentario a las SSTC 89 y 90/2019, en particular, proporcionalidad y test 
TS después ${ }^{10}$, terminaron por avalar su corrección desde un punto de vista jurídico. Es más, en lo que aquí nos interesa, el TC ni siquiera aplicó un test de proporcionalidad para enjuiciar el encaje constitucional de la medida, sino que se decantó por un simple control externo de la razonabilidad de la misma. Y la mejor doctrina ha elogiado esta forma de proceder. ${ }^{11}$.

Con todo ello se quiere evidenciar, antes de cerrar este excursus, que el Derecho de la excepción tiene un método característico, y su enjuiciamiento difícilmente puede abordarse en la práctica desde las categorías propias de la normalidad. Evidentemente, debe existir un control jurisdiccional -también político- de las mismas, pues el estado de derecho es resistente a la excepción ${ }^{12}$, pero la práctica ha demostrado que el canon interpretativo empleado por el TC en este tipo de escenarios no puede ser el mismo que rige durante la normalidad. Ante una emergencia constitucional no reglada, inevitablemente, cobran protagonismo los principios de urgencia, necesidad, proporcionalidad e, incluso como se ha visto, de mera razonabilidad.

Es precisamente en estos principios en los que nos debemos apoyar -retomando ya nuestro hilo argumental- para concluir la constitucionalidad del artículo 10 RD 463/2020. En efecto, parece más razonable interpretar con flexibilidad el RD 463/2020 y la LOAES que hacerlo con rigidez. Máxime cuando, como ya se ha apuntado, la adopción de estas medidas en el marco del estado de excepción, pese a la literalidad del artículo 26 LOAES, tampoco encuentra un fácil acomodo en términos de constitucionalidad. La alternativa no podía ser, creemos, en un momento en el que el aprovisionamiento de mascarillas no estaba garantizado, dejar que el comercio continuase abierto con normalidad y el virus propagándose cada vez a una velocidad mayor.

de necesidad o razonabilidad de las medidas", Teoría y Realidad Constitucional, núm. 44, 2019, pp. 503-523.

${ }_{10}$ MEJIA NAVARRO, I., "La aplicación del artículo 155 de la Constitución. Comentario a la Sentencia del Tribunal Supremo 277/2019, de 4 de marzo. Recurso Contencioso-administrativo núm. 659/2017", Revista de las Cortes Generales, núm. 109, 2020, pp. 641-653.

11 ARAGÓN REYES, M., "Tribunal Constitucional y consolidación del Estado: una mirada institucional", ponencia impartida en el marco de la Jornada "Miradas diferentes al Tribunal Constitucional", organizada por la Fundación Manuel Giménez Abad el 16 de febrero de 2021.

${ }^{12}$ CRUZ VILLALÓN, P., "El nuevo Derecho de excepción", op. cit. En este mismo sentido, es reveladora la posición de la Comisión de Venecia a este respecto. Cfr. CASTELLÀ ANDREU, J. M., "La Comisión de Venecia y los estados de emergencia: la necesaria preservación del Estado de Derecho y la democracia constitucional durante la crisis de la covid-19", en BIGLINO CAMPOS, P. y DURÁN ALBA, F. (Dirs), Los efectos horizontales de la covid sobre el sistema constitucional, Fundación Manuel Giménez Abad, Zaragoza, 2020. 
El cierre del comercio minorista era una medida necesaria y razonable para reducir la movilidad social y contener la propagación del virus. Asimismo, se trataba de una medida complementaria que perseguía garantizar la observancia de las restricciones impuestas a la libertad ambulatoria de los ciudadanos. Por todo ello, en un contexto de emergencia, y ante una situación perentoria en la que la inacción hubiese provocado unos perjuicios inconmensurables, cabe hacer un esfuerzo interpretativo con base en los principios antedichos para concluir que la suspensión temporal de la actividad empresarial no comportó una vulneración del contenido esencial del derecho a la libertad de empresa.

Es plausible que una interpretación jurídica conforme a los cánones de la normalidad, que analizaremos más adelante, nos haría concluir lo contrario. Sin embargo, en un contexto de crisis sanitaria sin precedentes, parece que la legitimidad del Tribunal Constitucional no se verá socavada si, tensionando los límites hermenéuticos, concluyese que la suspensión temporal de la actividad empresarial fue una mera limitación, intensísima si se quiere, del derecho reconocido en el artículo $38 \mathrm{CE}$.

Idéntica consideración, aunque con un acomodo más sencillo en el término "intervención", cabe hacer en relación a las medidas previstas en el artículo 14 RD 463/2020, en el que se contemplaban limitaciones a la actividad de las empresas de transportes. En una situación crítica como la vivida en aquellos meses resultaba necesario reducir los desplazamientos a lo largo del territorio nacional y, en consecuencia, fue razonable constreñir la oferta de transporte público de viajeros por carretera, ferroviario, aéreo y marítimo.

En el estado de alarma declarado en octubre (RD 926/2020, de 25 de octubre) no fueron acordadas, directamente, limitaciones a la actividad económica. No obstante, la introducción de un toque de queda entre las 23:00 y las 06:00 horas del día siguiente -modulable, dentro de unas horquillas, por el poder autonómico- afectó mediatamente al sector del ocio nocturno, que se vio obligado en la práctica a cerrar. Incluso en algunas CCAA, como se tendrá ocasión de comprobar, se acordó directamente el cierre de estas actividades (vid. II.3). Asimismo, la posibilidad que el RD 926/2020 otorgaba a las CCAA para acordar confinamientos perimetrales (municipales, provinciales y autonómicos), terminó por provocar el cierre de otras actividades (hostelería, restauración) en áreas de gran afluencia turística, como aquellas zonas de 
montaña especializadas en el sector de la nieve, que se nutren de esquiadores provenientes de un ámbito geográfico muy amplio.

Sin embargo, el RD 926/2020 no contempla una restricción directa del derecho a la libertad de empresa. Y, por ello, reprochar a esta norma la vulneración del artículo 38 CE no resulta posible. De hecho, el RD 926/2020 también ha sido impugnado ante el Tribunal Constitucional, pero a diferencia de lo ocurrido en relación al $\mathrm{RD} 463 / 2020$, los recurrentes no alegaron en este caso una vulneración del artículo $38 \mathrm{CE}^{13}$.

Indudablemente, la ausencia de un límite expreso a la libertad de empresa en el RD 926/2020, no impidió que esta norma tuviese un impacto más que notorio en este derecho. Pero con ello lo que se evidencia es que, con una alta probabilidad, lo previsto en el artículo 7 RD 463/2020, con independencia de lo establecido en el artículo 10 de dicha norma, hubiese bastado para provocar, indirectamente, el cierre de toda actividad comercial no esencial. $Y$ de haber sido así, al igual que ocurrió en relación al RD 926/2020, no habría cabido alegar una violación del artículo $38 \mathrm{CE}$ en el recurso de inconstitucionalidad interpuesto contra el RD 463/2020.

Por ello se apuntaba ut supra que la verdadera clave de bóveda del estado de alarma declarado en marzo fueron las restricciones introducidas a la libertad ambulatoria reconocida en el artículo 19 CE. Y, por ello, todo apunta a que el TC deberá centrar sus esfuerzos en determinar la constitucionalidad de lo contemplado en el artículo 7 RD 463/2020, también impugnado.

En todo caso, la crisis sanitaria desencadenada en 2020 ha puesto de relieve que la excepcionalidad es, por definición, imprevisible. Y que, por ello, sería más que pertinente acometer una reforma del Derecho de excepción que permita a los poderes públicos, con garantías, pero también con flexibilidad, adaptarse a los infortunios que, a buen seguro -certus an, incertus quando-, están por venir.

El control jurisdiccional, por parte del TC, y el político, por parte del Congreso de los Diputados, resultan esenciales $y$, por ello, ineludibles ${ }^{14}$. Pero la

13 Contenido disponible en línea: https://www.voxespana.es/wpcontent/uploads/2020/11/RECURSO-INCONSTITUCIONALIDAD.pdf [última consulta: enero 2021]

${ }^{14}$ Parecen, desde luego, más pertinentes que un control judicial acometido por la jurisdicción ordinaria, tal y como han venido defendiendo quienes han apostado por superar la crisis sanitaria recurriendo al Derecho de la normalidad. El recurso al Derecho de excepción permite 
regulación del Derecho de excepción debe de ser lo suficientemente abierta para, sin tensionar las costuras de la interpretación jurídica, poder dar una respuesta adecuada a los retos que acontezcan. La regulación constitucional de la coerción estatal, y en buena medida el desarrollo jurisprudencial que de esta figura ha realizado la STC 89/2019, pueden ser un buen punto de partida $^{15}$.

\section{La intervención de empresas privadas y la requisa de bienes como medida para afrontar la crisis sanitaria}

Como ya sabemos, la literalidad del artículo 11 c) LOAES faculta al poder público para intervenir empresas privadas (industrias, fábricas, talleres, explotaciones o locales de cualquier naturaleza, con excepción de domicilios privados). Igualmente, dicha disposición, aunque en su letra b), permite a la autoridad practicar requisas temporales de todo tipo de bienes e imponer prestaciones personales obligatorias. Aparentemente, esta segunda previsión parece afectar a particulares y no a empresas, o al menos no a empresas del sector terciario, pero lo cierto es que ambas figuras permiten conseguir resultados muy similares, al menos, si los preceptos son interpretados con flexibilidad. Máxime si se tiene en consideración que el Derecho de la normalidad contempla la posibilidad de adoptar estas medidas al margen de lo previsto en el artículo 116 CE $^{16}$. De hecho, los Reales Decretos 426/2020 y 926/2020 tan solo habilitaron la posibilidad de que la autoridad pública acordase prestaciones personales obligatorias y, solo en el caso del RD

un triple control: jurisdiccional y político en un primer lugar, y judicial ulteriormente, sobre los actos de aplicación. No obstante, es cierto que en la práctica ambos modelos se han aproximado mucho, atendiendo a la inexistencia de un cauce procesal que permita al TC pronunciarse con rapidez sobre la constitucionalidad de las medidas adoptadas, y a la decisión del Congreso de los Diputados de autorizar una prórroga amplísima, hasta mayo, del estado de alarma declarado en octubre.

${ }^{15}$ La remisión a una ley orgánica en el artículo 116.1 CE, a diferencia de lo que ocurre en el artículo $155 \mathrm{CE}$, obliga a que sea parcialmente el legislador, y no solo el TC, el encargado de definir los términos en los que debe regularse una emergencia de naturaleza no políticoterritorial. Sin embargo, parece oportuno que aquel renuncie a regular de manera exhaustiva la excepcionalidad, pues puede ser una tarea hercúlea y, muy posiblemente, abocada al fracaso.

${ }^{16}$ Artículo 26.1 Ley 14/1986, de 25 de abril, General de Sanidad (LGS). 
426/2020, también requisas temporales de bienes. Pero en ningún caso previeron la intervención de empresas ${ }^{17}$.

Una prestación personal en sentido estricto, en el escenario que nos movemos, sería la prórroga de la contratación de los médicos residentes en el último año de formación en determinadas especialidades (postergando su paso a la condición de médico adjunto, con el consiguiente perjuicio retributivo), tal y como fue acordado por Orden SND/232/2020, de 15 de marzo, por la que se adoptan medidas en materia de recursos humanos y medios para la gestión de la situación de crisis sanitaria ocasionada por la covid-19. O, en idéntico sentido, y acordado también por esta resolución, el establecimiento de un régimen estricto de vacaciones, permisos y licencias del personal sanitario, para tratar de contar con el máximo número de efectivos disponibles y evitar así, o al menos mitigar, la saturación de los centros hospitalarios.

Sin embargo, estas medidas, exceptuando quizás la posibilidad de prohibir al personal sanitario prestar servicio simultáneamente en la sanidad privada, no tienen impacto en la actividad económica -entendida esta como mercado: es decir, como el conjunto de actividades realizadas libremente por los agentes económicos sin intervención del poder público-, que es precisamente el objeto de este capítulo.

Por el contrario, sí que han tenido un impacto incuestionable en la actividad económica otras decisiones, tales como, en primer lugar, la posible ocupación de clínicas privadas, ante la saturación padecida por la sanidad pública en los momentos de mayor presión asistencial. También se debe hacer referencia a la puesta a disposición del sector público de centros, servicios y establecimientos de diagnóstico clínico para la detección de casos positivos por covid-19. Cabe aludir igualmente a la imposición de determinadas obligaciones a residencias de mayores de carácter privado (que podían ser obligadas a acoger a residentes de otro centro residencial en determinados supuestos). $\mathrm{Y}$, por último, se puede destacar el acopio de material, como equipos de protección individual, respiradores, mascarillas, viales y un largo etcétera en el que pueden incluirse los medicamentos.

${ }^{17}$ Artículos 8 RD 463/2020 y 11 RD 926/2020. En el RD 926/2020 tan solo está contemplada la posibilidad de imponer prestaciones personales obligatorias, y no requisas temporales. Una cuestión no menor que, como se verá, ha tenido consecuencias en el plano práctico. 
¿Requisa temporal de bienes o verdadera intervención? La cuestión, en este caso, sí que parece baladí. Al menos en lo que se refiere al estado de alarma declarado en marzo. Ambas posibilidades están contempladas por la LOAES y, si bien el RD 463/2020 tan solo prevé la requisa temporal, los consabidos principios de urgencia, necesidad y proporcionalidad exigen una interpretación flexible del marco jurídico de la excepción. De hecho, prácticamente todas las medidas señaladas fueron implementadas durante la primera ola de la pandemia, con la salvedad de la ocupación de clínicas privadas ${ }^{18}$.

Esta medida, no obstante, fue contemplada en abstracto por el punto octavo de la antedicha Orden SND/232/2020, de 15 de marzo ${ }^{19}$. Pero tal disposición se limitaba a prever que, el poder autonómico, en el caso de no poder atender adecuadamente a sus ciudadanos con los medios materiales y personales públicos, podía servirse de los centros y establecimientos sanitarios privados, su personal, y las Mutuas de accidentes de trabajo. Y fue el poder autonómico, durante la primera ola de la pandemia, el que optó por no activar esta posibilidad.

Puede que la magnitud de la pandemia, y el reducido tamaño del sector privado en la mayoría de Comunidades Autónomas con la salvedad de Cataluña, moviese a los poderes autonómicos a adoptar medidas de mayor calado, como la puesta en marcha de un hospital de campaña en los pabellones 7 y 9 del recinto ferial de IFEMA. También es razonable pensar que, dadas las circunstancias, los centros privados se encontrasen en una situación similar a los públicos, deviniendo ineficaz su intervención.

Sin embargo, lo cierto es que, durante estos meses, un número muy importante de pacientes de la sanidad pública ha sido atendido en centros privados. Si bien, la técnica jurídica a la que se ha recurrido para posibilitar esta solución, que a la postre ha coadyuvado a paliar la saturación del sistema público de

\footnotetext{
${ }^{18}$ En relación a las pruebas diagnósticas, Orden SND/344/2020, de 13 de abril, por la que se establecen medidas excepcionales para el refuerzo del Sistema Nacional de Salud y la contención de la crisis sanitaria ocasionada por la covid-19. Respecto a las medidas sobre residencias de mayores, Orden SND/275/2020, de 23 de marzo, por la que se establecen medidas complementarias de carácter organizativo, así como de suministro de información en el ámbito de los centros de servicios sociales de carácter residencial en relación con la gestión de la crisis sanitaria ocasionada por la covid-19. Y en punto al abastecimiento de determinados bienes, como los medicamentos, Orden SND/276/2020, de 23 de marzo, por la que se establecen obligaciones de suministro de información, abastecimiento y fabricación de determinados medicamentos en la situación de crisis sanitaria ocasionada por la covid-19.

${ }_{19}$ La norma no es dictada bajo la cobertura normativa que le otorgaba el artículo 26.1 LGS, sino bajo el régimen jurídico de la excepción.
} 
salud, no ha sido la intervención de los centros privados, sino la derivación. El recurso a esta técnica, sin embargo, plantea un problema fundamental: la determinación del precio por los servicios prestados. En efecto, de abordarse el recurso a camas privadas desde la técnica de la intervención, los servicios prestados pueden ser valorados sin seguir una lógica de mercado ${ }^{20}$.

Sobre este particular se volverá en el epígrafe III de este trabajo. Ahora hay destacar que, ya en el marco de la segunda ola, y habiendo sido declarado un nuevo estado de alarma por RD 926/2020, algunas Comunidades Autónomas sí que recurrieron a intervenir centros hospitalarios privados. Cabe traer a colación aquí una Resolución de la Consejería de Sanidad de la Comunidad Valenciana, de 12 de noviembre ${ }^{21}$, por la que se acordó poner a disposición de la Comunidad Autónoma los centros hospitalarios privados y su personal.

La norma fue dictada durante la vigencia del Real Decreto 926/2020 pero, al no contemplar esta norma ni la intervención de empresas ni la requisa temporal de bienes -tan solo alude esta disposición, en su artículo 11, a la posibilidad de imponer prestaciones personales-, la Generalitat valenciana tuvo que recurrir al Derecho de la normalidad para adoptar esta medida. En concreto, la misma se fundamenta en un amplio abanico normativo: artículo 3 Ley Orgánica 3/1986, de 14 de abril, de Medidas Especiales en Materia de Salud Pública, artículo 26.1 Ley 14/1986, de 25 de abril, general de sanidad y el artículo 54 Ley 33/2011, de 4 de octubre, general de salud pública.

De todas estas disposiciones, creemos que aquella que da verdadero soporte normativo a la decisión de la Generalitat es el artículo 26 LGS. El artículo 3 LOSP, por su inconcreción, no cumple con los estándares establecidos en la jurisprudencia constitucional en punto a la determinación de los límites

\footnotetext{
${ }^{20}$ F. PLASENCIA SÁNCHEZ ha considerado, como una fórmula alternativa a la intervención o la requisa, la suscripción de contratos de emergencia bajo el paraguas del artículo 120 de la Ley 9/2017, de 18 de noviembre, de Contratos del Sector Público -cuya aplicación se generalizó por lo previsto en el artículo 16 Real Decreto-Ley 7/2020, de 12 de marzo-. Cfr. "Repensar las requisas: las nuevas realidades exigen una nueva regulación", en RECUERDA GIRELA, M. A.., Antes de la próxima pandemia, Thomson Reuters, Navarra, 2020, pp. 271-284. Sin embargo, parece existir una diferencia no menor entre estas técnicas. Y es que, en estos contratos, la valoración del servicio o producto adquirido por el poder público es valorado a precio de mercado.

${ }^{21}$ Resolución de 12 de noviembre de 2020, de la Consellera de Sanidad Universal y Salud Pública, para la puesta a disposición del Sistema Valenciano de Salud de los medios, recursos, centros y establecimientos sanitarios privados, y mutuas de accidentes de trabajo. 
impuestos a los derechos fundamentales ${ }^{22}$. Y la libertad de empresa, como tendremos ocasión de comprobar, es un derecho fundamental más. Por otro lado, creemos que el artículo 54 LGSP, interpretado teleológica y sistemáticamente, permite acordar el cierre o intervención de una empresa por razones de salubridad, pero más difícilmente puede servir de soporte para intervenir de manera generalizada un sector económico por razones de necesidad. En efecto, como es sabido, en el régimen jurídico de la normalidad, las normas limitadoras de derechos deben ser interpretadas de manera restrictiva.

El artículo 26 LGS, por el contrario, constituye un anclaje normativo sólido en el que justificar la decisión adoptada por el gobierno valenciano. Y, por ello, y a diferencia de la situación analizada en el subepígrafe anterior, no estamos ahora ante una emergencia no reglada. Puede resultar llamativo que el RD 926/2020 eludiese deliberadamente hacer alusión a alguna de las medidas contempladas en la LOAES, y que habían sido expresamente activadas durante la primera ola de la pandemia. Sin embargo, el ordenamiento jurídico ordinario también permite la adopción de esta medida. $Y$, como se tendrá ocasión de comprobar (vid. III), el recurso a una u otra rama del ordenamiento -normalidad y excepcionalidad- no tiene mayor trascendencia; pues el régimen indemnizatorio contemplado es el mismo, con independencia de que la intervención se produzca bajo el régimen jurídico de la normalidad o de la excepción.

En todo caso, y para concluir este subepígrafe, cabe añadir que la determinación de la licitud de esta medida corresponderá a la jurisdicción contencioso-administrativa. Lo único que ha quedado acreditado hasta aquí es que el poder autonómico adoptó esta decisión respetando el principio de legalidad. Llegados a este punto, en última instancia y atendiendo a las circunstancias concretas del caso, corresponde al poder judicial determinar si dicha decisión fue proporcionada, atendiendo a los consabidos juicios de idoneidad, necesidad y proporcionalidad en sentido estricto.

${ }^{22}$ Cfr. SÁENZ ROYO, E., "Limitar derechos fundamentales durante la pandemia", Agenda Pública-Fundación Manuel Giménez Abad, 14 de julio de 2020. Disponible en línea: https://agendapublica.es/limitar-derechos-fundamentales-durante-la-pandemia/ 


\section{Otras medidas limitadoras de la actividad económica: la normalidad en la excepción}

Tal y como se anticipaba, no todas las medidas adoptadas durante la vigencia del Derecho constitucional de excepción fueron adoptadas bajo el régimen jurídico de la excepcionalidad. De hecho, cuantitativamente, la mayor parte de las medidas acordadas durante estos meses con una repercusión en el mercado han sido tomadas bajo el paraguas del Derecho de la normalidad.

A título de ejemplo podemos destacar algunas de ellas, tales como, en primer lugar, la imposibilidad de que los suministradores de energía eléctrica, gas natural y agua suspendan el suministro a aquellos consumidores en los que concurra la condición de consumidor vulnerable, vulnerable severo o en riesgo de exclusión social (art. 4 Real Decreto-Ley 8/2020, de 17 de marzo). También cabe señalar la introducción de medidas para permitir la moratoria de la deuda hipotecaria para la adquisición de la vivienda habitual (art. 7 Real Decreto-Ley 8/2020, de 17 de marzo) o la suspensión de los procedimientos de desahucio (art. 1 Real Decreto-Ley 11/2020, de 31 de marzo). Igualmente cabe hacer alusión a la garantía en el suministro de los servicios de telecomunicaciones e, incluso, la prohibición de cambiar de operador durante la vigencia del estado de alarma (arts. 18 a 20 Real Decreto-Ley 8/2020, de 17 de marzo). Todavía en el marco de la primera ola de la pandemia, y quizás por su incuestionable trascendencia, hay que destacar muy especialmente el permiso retribuido recuperable para las personas trabajadoras por cuenta ajena que no prestaban servicios esenciales y que comportó, en la práctica, el cierre de la práctica totalidad de la actividad económica entre los días 30 de marzo y 9 de abril (Real Decreto-Ley 10/2020, de 29 de marzo). Ya en el marco del segundo estado de alarma, entre las medidas más reseñables, destaca la reducción de los alquileres de inmuebles no destinados a vivienda siempre que el arrendador sea un gran propietario (art. 1 Real Decreto-Ley 35/2020, de 22 de diciembre) $\mathrm{y}$, a nivel autonómico, la totalidad de CCAA acordaron reducciones de aforos y limitaciones de horarios de gran parte de establecimientos comerciales (v. gr., entre muchas otras, Ley $3 / 2020$, de 3 de diciembre, por la que se establece el 
régimen jurídico de alerta sanitaria para el control de la pandemia covid-19 en Aragón $\left.{ }^{23}\right)$.

Es evidente que para reflexionar sobre la validez de todas estas medidas -que no dejan de ser, a lo sumo, sino algunas de las más significativas- es imprescindible acudir al régimen jurídico que disciplina la libertad de empresa durante la normalidad. Vayamos a ello.

\section{A) Límites al legislador ordinario y libertad de empresa}

La libertad de empresa es un derecho reconocido en el artículo $38 \mathrm{CE}$, cuya regulación en la Sección $2^{ }$, del Capítulo $\mathrm{II}$, del Título I no le resta la consideración de fundamental ${ }^{24}$. Como tal, su regulación debe acometerse en una norma con rango de ley, que deberá respetar en todo caso su contenido esencial (art. $53 \mathrm{CE})$.

En este sentido, el TC comenzó estableciendo que el contenido esencial del derecho fundamental reconocido en el artículo 38 CE está integrado por el derecho a iniciar y mantener en el tiempo una actividad empresarial (STC 225/1993, de 8 de julio). Sin embargo, también se debe recordar que, más recientemente, el TC ha renunciado a una concepción absolutista de los derechos fundamentales $y$, a la hora de determinar cuándo una iniciativa legislativa vulnera el contenido esencial de un derecho, viene recurriendo al test de proporcionalidad de origen germano ${ }^{25}$. De modo que, en la práctica, no se trata ya de determinar si la regulación legal de un derecho se inmiscuye en su contenido esencial, sino que lo que debe establecerse es si dicha intromisión era, o no, proporcionada ${ }^{26}$.

\footnotetext{
${ }^{23}$ Consecuencia de la tramitación como proyecto de ley por el procedimiento de urgencia del Decreto-Ley 7/2020, de 19 de octubre, del Gobierno de Aragón, por el que se establece el régimen jurídico de alerta sanitaria para el control de la pandemia covid-19 en Aragón.

24 El hecho de estar protegido por menos garantías que los derechos reconocidos por el constituyente en la Sección 1ํㅡㄹ del Capítulo II, del Título I no es un argumento bastante para negar a la libertad de empresa, y al resto de derechos de la Sección $2^{\circ}$, la condición de fundamental. De razonar en estos términos, solo cabría concluir, absurdamente, que toda Constitución que no reconoce la categoría de la ley orgánica o del recurso de amparo, como la estadounidense, no cuenta con verdaderos derechos fundamentales. Cfr. RUBIO LLORENTE, F., "La libertad de empresa en la Constitución", en IGLESIAS PARDA, J. L. (Coord.), Estudios jurídicos en homenaje al profesor Aurelio Menéndez, Civitas, Madrid, 1996, pp. 431-446.

${ }^{25}$ Cfr. DíEZ PICAZO, L. M., Sistema de derechos fundamentales, Civitas, Cizur Menor, 2013, pp. 111-114.

${ }^{26}$ A. CIDONCHA MARTÍN denuncia que, de facto, la posible constitucionalidad de una medida restrictiva de la libertad de empresa ya no se aborda "también" desde la perspectiva del 
Sin embargo, también debe tenerse presente que, en cuanto a la libertad de empresa se refiere, el TC ha sustituido este test de proporcionalidad por un simple test de razonabilidad en el que tan solo se tiene en consideración la idoneidad de la medida para alcanzar el fin perseguido -bastando con que el mismo sea legítimo y con independencia, incluso, de que se encuentre plasmado en la Constitución- (recientemente, STC 53/2014, de 10 de abril) ${ }^{27}$. EI TC, en relación a la libertad de empresa, y a diferencia de la forma en la que procede respecto al resto de derechos fundamentales, se ha decantado por renunciar a dos elementos del test de proporcionalidad (necesidad y proporcionalidad en sentido estricto) para enjuiciar la intervención del legislador.

Con esta jurisprudencia, el máximo intérprete de la CE no hace sino seguir la estela marcada por algunos de sus homólogos, como la Corte Constitucional italiana o el Consejo Constitucional francés ${ }^{28}$. Y esta senda comporta, primero, acentuar la dimensión objetiva del derecho a la libertad de empresa en detrimento de la dimensión subjetiva ${ }^{29}$ y, segundo, otorgar un amplísimo

contenido esencial, sino "solo" desde la constitucionalidad de los límites con base en el principio de proporcionalidad. Cfr. La libertad de empresa, op. cit., p. 279.

${ }^{27}$ Desde 2016 (STC 35/2016, de 3 de marzo), cuando el TC enjuicia medidas limitativas para el acceso al mercado, no relativas al mantenimiento en el mismo, este órgano jurisdiccional recurre, junto a un test de idoneidad, a otro de necesidad. Es lo que Cidoncha Martín ha considerado un test de proporcionalidad "mutilado", por renunciar al último elemento del test de proporcionalidad, a saber, que la medida limitativa de un derecho sea proporcional en sentido estricto. Cfr. CIDONCHA MARTÍN, A., "Coronavirus y libertad de empresa", en BIGLINO CAMPOS, P. y DURÁN ALBA, F., Los efectos horizontales de la covid sobre el sistema constitucional, Fundación Manuel Giménez Abad, Zaragoza, 2020.

28 ARAGÓN REYES, M., "Constitución económica y libertad de empresa", en IGLESIAS PARDA, J. L. (Coord.), Estudios jurídicos en homenaje al profesor Aurelio Menéndez, Civitas, Madrid, 1996, p. 176.

${ }^{29}$ Aragón Reyes ha señalado que la protección eficaz de un derecho como el que aquí nos ocupa consiste realmente en las vías de control de constitucionalidad de las leyes, a saber, y como se apuntaba, en la dimensión objetiva del derecho. El TC, sin embargo, lo que viene sosteniendo en sentido estricto es que el artículo $38 \mathrm{CE}$ contiene un derecho en el que predomina el carácter de "garantía institucional" (STC 83/1984, de 24 de julio), aunque sin negarle su condición de derecho fundamental. Y por ello Cidoncha Martín, quien ha abordado de manera pormenorizada esta cuestión, apunta que el TC no distingue con toda la claridad que procedería entre derecho fundamental y garantía institucional. Cfr. ARAGÓN REYES, M., "Constitución económica y libertad de empresa", op. cit.s. 177 y CIDONCHA MARTíN, A., La libertad de empresa, Thomson Civitas, Cizur Menor, 2006, p. 185. Si el TC hubiese mantenido una concepción absolutista de los derechos fundamentales, esta disquisición podría no tener más recorrido, atendiendo a que, en ambos supuestos, la clave de bóveda que determina la licitud de la intervención del legislador, parece ser la recognoscibilidad del derecho-institución después de que esta tenga lugar (STC 11/1981, de 8 de abril, en cuanto a los derechos fundamentales se refiere y STC 32/1981, de 28 de julio, en materia de garantías institucionales). Sin embargo, como ya se ha apuntado, desde la STC 55/1996, de 28 de marzo, el TC recurre a un test de proporcionalidad para enjuiciar la regulación legal de los derechos fundamentales. $\mathrm{Y}$, en cuanto a la libertad de empresa se refiere, lo que resulta 
margen al legislador a la hora de abordar la configuración legal y los límites de este derecho.

El TC, en relación al artículo $38 \mathrm{CE}$, tan solo controla la idoneidad de la previsión legal para alcanzar un fin legítimo. En el caso que nos ocupa en este apartado, el fin legítimo perseguido por el legislador puede ser de muy diversa índole. En la mayoría de las ocasiones, el interés protegido es el más evidente, la protección de la vida. Es el caso de las limitaciones de aforo o la reducción de los horarios de apertura. También es el caso del permiso obligatorio retribuido, implementado por Real Decreto-Ley 10/2020, que perseguía, siguiendo la Exposición de motivos de la norma, "limitar al máximo la movilidad" para contralar "la propagación del virus y evitar que el acúmulo de pacientes en las Unidades de Cuidados Intensivos lleve a su saturación". E, incluso, también puede esgrimirse que la vida es el interés protegido en la prohibición de cambiar de operador durante la vigencia del estado de alarma, a la que se ha hecho referencia, por pretender esta medida evitar "que los ciudadanos tengan que desplazarse físicamente a centros de atención presencial a clientes de los operadores de telecomunicaciones 0 de que estos tengan que realizar intervenciones físicas en los domicilios de los clientes" (Exposición de Motivos Real Decreto-Ley 8/2020). En ocasiones, no obstante, el interés perseguido por el legislador no es la preservación de la vida, pero no por ello deja de ser un interés legítimo. Éste es el caso, por ejemplo, de la reducción de los alquileres de inmuebles no destinados a vivienda siempre que el arrendador sea un gran propietario, que persiguen evitar la incapacidad financiera de autónomos y pymes para hacer frente al cumplimiento, total o parcial, de sus obligaciones de pago de las rentas (Exposición de Motivos Real Decreto-Ley 35/2020, de 22 de diciembre).

Lo cierto es que buena parte de estas medidas, que constriñen la capacidad del empresario para organizar los medios de producción e, incluso, falsean la competencia, pilar básico del libre mercado, solo deberían tener cabida en un contexto de crisis sanitaria. En este marco quedan plenamente justificadas. Sin embargo, al haber sido excluidos los juicios de necesidad y de proporcionalidad en sentido estricto del test empleado por el TC para enjuiciar estas medidas,

paradójico es que, siendo considerada un derecho fundamental, para acometer dicho enjuiciamiento se renuncie a dos elementos del test de proporcionalidad (necesidad y proporcionalidad en sentido estricto) que sí son empleados en relación al resto de derechos. 
cabe la posibilidad de que las mismas puedan ser adoptadas, también, en un contexto de normalidad no adjetivada, ni nueva, ni vieja.

Puede que, en una situación ordinaria, algunas de estas medidas sean excesivas, y en consecuencia no necesarias. $Y$ muy probablemente, las mismas irrogarán unos perjuicios muy superiores a las ventajas que persiguen, no superando consecuentemente el juicio de proporcionalidad en sentido estricto. Sin embargo, las mismas, con independencia de las circunstancias, siempre resultarán idóneas para el fin que dicen perseguir. $Y$ por ello, atendiendo a la jurisprudencia del TC a este respecto, serán conformes a la Constitución. Una conclusión que no hace sino evidenciar los problemas que acarrea el recurso por parte del TC a un test de proporcionalidad mutilado para evaluar las medidas limitadoras de la libertad de empresa (art. $38 \mathrm{CE}$ ). Máxime cuando, el empleo por parte del TC del test de proporcionalidad en plenitud, no habría impedido al legislador adoptar, bajo el paraguas del Derecho de la normalidad, pero en un contexto de crisis sanitaria, las medidas que se acaban de aludir: por idóneas, necesarias y proporcionales en sentido estricto atendiendo a la situación padecida durante los últimos meses ${ }^{30}$.

Una vez establecido el margen de actuación del legislador a la hora de regular la libertad de empresa como derecho fundamental, también procede determinar si dicha función puede ser asumida por el legislador de urgencia. Máxime cuando la práctica totalidad de las decisiones adoptadas durante estos meses, bajo el régimen jurídico de la normalidad, pero en un escenario crítico, han sido adoptadas por decreto-ley.

En relación a este particular, como es sabido, debe estudiarse si la regulación supera los límites formales y materiales establecidos en el artículo 86 CE. En punto a los límites formales, es incuestionable que en todos los supuestos

30 Además, el recurso al test de proporcionalidad completo tampoco habría impedido, probablemente, la adopción de otras medidas cuya vigencia, incluso, podría verse proyectada una vez que la pandemia sea superada, por pretender la tutela de otros intereses diferentes a la protección de la vida en sentido estricto. Nos referimos, por ejemplo, a la imposibilidad de que los suministradores de energía eléctrica, gas natural y agua suspendan el suministro a determinados consumidores. En los detalles, desde luego, estará la diferencia, pero es posible pensar en una regulación compatible con dicho objetivo y que supere el triple juicio de proporcionalidad. Podemos destacar el camino iniciado por la Ley 24/2015, de 29 de julio, de medidas urgentes para afrontar la emergencia en el ámbito de la vivienda y la pobreza energética, cuya Exposición de Motivos recuerda que la Observación general número 4 del Comité de Derechos Económicos, Sociales y Culturales de las Naciones Unidas al PIDESC, el contenido del derecho a la vivienda comprende el acceso permanente a recursos naturales y comunes, a agua potable y a energía para la cocina, la calefacción y la luz, y el derecho al agua. 
antedichos concurre el supuesto habilitante (extraordinaria y urgente necesidad) y, además, existe una conexión de sentido entre este presupuesto y las medidas contenidas en las normas. Desde el punto de vista material, como se recordará, la legislación de urgencia no puede afectar a los derechos fundamentales reconocidos en el Título I de la Constitución, entre los que se encuentra la libertad de empresa. Sin embargo, el TC ha entendido que, por afectar, debe entenderse la regulación integral de un derecho o aquella que incida en aspectos sustanciales del mismo. $Y$ ha admitido, además y en todo caso, que la capacidad que tiene la legislación de urgencia para afectar a un derecho fundamental dependerá de la configuración constitucional del derecho y de su colocación en el texto constitucional (STC 111/1983, de 2 de diciembre). Teniendo en consideración, en primer lugar, que las decisiones adoptadas no han afectado como norma general a aspectos sustanciales del derecho y conociendo, en segundo lugar, que a la libertad de empresa está ubicada sistemáticamente en la Sección $2^{\circ}$ del Capítulo II del Título I, parece que lo más acertado es concluir que la fuente del Derecho a la que se ha recurrido mayoritariamente para adoptar medidas limitadoras de la actividad de empresa ha sido acertada desde un punto de vista constitucional.

\section{B) Poder autonómico y restricciones a la libertad de empresa}

En las líneas que preceden se ha hecho referencia a la capacidad que asiste al poder central para limitar la actividad económica. Dichas medidas, es evidente, para ser constitucionalmente válidas, deberán tomarse de conformidad con el sistema de distribución de competencias. Si bien es cierto que, atendiendo a la

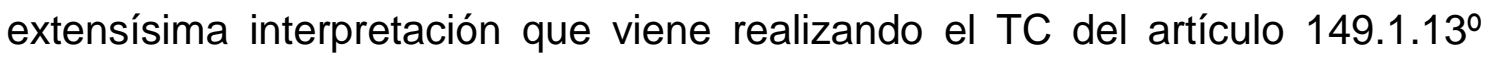
CE, ninguna de las decisiones adoptadas por el Estado durante estos meses parece revestir problemas desde el punto de vista competencial.

Reviste un mayor interés, sin embargo, analizar las posibilidades que asisten a los poderes autonómicos para acordar medidas sobre este mismo particular. Una situación nada infrecuente, por cierto, durante estos últimos meses y, muy especialmente, a partir de la fingida normalidad que aconteció entre julio y finales de octubre, y del estado de alarma declarado por RD 926/2020.

En un contexto de crisis sanitaria, las CCAA han procedido, fundamentalmente, a limitar los aforos de determinados establecimientos (comercio, hostelería, restauración, gimnasios, mercadillos al aire libre, academias, eventos 
deportivos, cines, teatros, auditorios, casinos...). Estas medidas han sido acordadas, con independencia de estar declarado un estado excepcional, con base en el Derecho de la normalidad, por ser las CCAA competentes en materia de salud pública ${ }^{31}$. Y, por ello, su licitud depende de todo cuanto aquí ha sido apuntado: establecimiento de los límites en una norma con rango de ley (ordinaria o, en su caso, de urgencia) e idoneidad de la medida.

Las CCAA comenzaron a establecer restricciones de aforo a partir del mes de junio, durante la conocida como tercera fase de la desescalada y, con mayor intensidad, una vez que decayó el estado de alarma declarado por RD $463 / 2020^{32}$. El Estado, con base, al menos en lo que aquí interesa, en los artículos 149.1. 13ㅇy y 16으, CE, había dictado el Real Decreto-Ley 21/2020, de 9 de junio, que contenía una serie de disposiciones para regular la actividad de centros sanitarios y docentes, establecimientos comerciales y hoteleros, hostelería, equipamientos culturales, actividades deportivas... Si bien, esta norma se limitaba a establecer una distancia de seguridad de un metro y medio en las actividades antedichas, y remitía a las autoridades competentes, que no eran otras que las autonómicas, la adopción de las medidas pertinentes en punto al aforo, desinfección, prevención y acondicionamiento ${ }^{33}$. Las CCAA, en diferentes normas de rango reglamentario, desarrollaron esta previsión legal, y comenzaron a establecer limitaciones de aforo y, también, y yendo más allá de la literalidad del RD-Ley 21/2020, limitaciones horarias a la apertura de determinados establecimientos.

Las decisiones autonómicas de limitar, reglamentariamente, los aforos de determinados establecimientos, pueden estar amparadas por la habilitación

${ }^{31}$ En los estatutos de segunda generación esta competencia aparece recogida con mayor claridad (v. gr. art. 71. 55 EAAr), pero ello no obsta para que la totalidad de normas institucionales básicas de las CCAA atribuyan a dicho nivel de poder competencias en la materia.

${ }^{32}$ Durante la vigencia del estado de alarma de marzo-junio se puso de relieve que el artículo 116 CE contenía un título competencial universal a favor del centro, relacionándose por el principio de prevalencia (art. 149.3 CE) las normas autonómicas y estatales en materia de aforos. Es decir, prevaleciendo las previsiones estatales sobre las autonómicas. Cfr. VELASCO CABALLERO, F., "Estado de alarma y distribución territorial del poder", El Cronista del Estado Social y Democrático de Derecho, núm. 86-87, pp. 78-87.

${ }^{33}$ Teniendo en consideración que el Estado, con el aval del TC, venía realizando una interpretación muy generosa de algunos de estos títulos competenciales, en particular de la cláusula de naturaleza horizontal prevista en el artículo 149.1.13 $\mathrm{CE}$, parece que el Real Decreto-Ley 21/2020 fue una buena muestra de self-restraint por parte del centro. 
legal contenida en el Real Decreto-Ley $21 / 2020^{34}$. Sin embargo, la cuestión es más resbaladiza en punto a las limitaciones de horarios.

La reducción de los horarios de apertura era, posiblemente, una medida razonable desde un punto de vista epidemiológico. Sin embargo, como se ha apuntado, los derechos fundamentales -como la libertad de empresa- solo pueden ser limitados por ley, debiendo ser además dicho límite lo suficientemente concreto y establecer las condiciones y garantías de dicha restricción. Solo en el caso de cumplirse con este requisito cabe entrar a valorar la idoneidad de la medida.

Sin embargo, el Real Decreto-Ley 21/2020 no hacía ninguna referencia a los horarios de apertura. Además, a nivel subcentral existen normas con rango de ley, por ostentar las CCAA competencias en materia de comercio interior, que expresamente prevén unos horarios comerciales más amplios para determinados sectores de actividad. Ante esta tesitura, las CCAA esgrimieron como aplicable tanto el artículo 3 Ley Orgánica 3/1986, de Medidas Especiales en Materia de Salud Pública, como diferentes leyes subcentrales dictadas en materia de salud pública. Pero lo cierto es que resulta controvertida la justificación de una medida de este tenor en las disposiciones antedichas.

En el caso del artículo 3 LOSP, atendiendo a su inconcreción, y en relación a las leyes autonómicas de salud pública, debido a que una interpretación restrictiva -por tratarse de una norma limitadora de derechos- impediría ampliar el ámbito subjetivo de la misma de manera genérica. En efecto, las normas autonómicas de salud pública, interpretadas estrictamente, autorizan a la administración para cerrar determinados establecimientos por razones de salubridad, pero no para acordar una alteración indiscriminada de los horarios de apertura de cualquier establecimiento por razones de necesidad.

El poder autonómico terminó siendo consciente de que resultaba más que recomendable la aprobación de normas con rango de ley que diesen una cobertura jurídica adecuada a la toma de este tipo de decisiones. Así lo entendieron algunas Comunidades Autónomas, como Aragón, que aprobó la antedicha Ley $3 / 2020$, de 3 de diciembre, por la que se establece el régimen jurídico de alerta sanitaria para el control de la pandemia covid-19 en Aragón.

${ }^{34}$ Esta medida, además, era idónea para preservar la salud de los ciudadanos (y también necesaria y proporcionada en sentido estricto, a pesar de que el TC posiblemente no se hubiese detenido a analizar estos requisitos de haber sido impugnada esta disposición). 
La norma contempla la posibilidad de que la administración autonómica, en una situación de pandemia, acuerde limitaciones de aforos y de horarios. E, incluso, acuerde el cierre in totum de un determinado sector: el ocio nocturno (arts. 20, 29 y 32). Nos detendremos especialmente en el análisis de la ley aragonesa, al considerarla de especial interés por dos motivos.

El primero de ellos es que la misma regula, exclusivamente, el régimen jurídico de alerta sanitaria para el control de la pandemia covid-19, por lo que, en sentido estricto, la misma difícilmente podrá ser aplicada a otras crisis sanitarias que puedan acontecer en el futuro, pese a haber sido dictada bajo el Derecho de la normalidad y haber entrado en vigor de manera indefinida (DF-2). No debemos olvidar que la Ley $3 / 2020$ es consecuencia de la tramitación como proyecto de ley por el procedimiento de urgencia del DecretoLey 7/2020, de 19 de octubre, del Gobierno de Aragón, por el que se establece el régimen jurídico de alerta sanitaria para el control de la pandemia covid-19 en Aragón. Y que dicha norma, adoptada en un contexto de extraordinaria y urgente necesidad, estuvo marcada indudablemente por la pandemia provocada por el patógeno SARS-CoV-2. Sin embargo, parece que nada impide al legislador autonómico, aragonés o cualesquiera, dotarse de un marco normativo que le permita en el futuro enfrentarse de manera garantista a otros episodios que acontezcan de similar naturaleza al que vivimos estos días.

El segundo aspecto que se debe traer a colación, y con el que se cerrará este epígrafe, es la posibilidad contemplada en la Ley 3/2020 de acordar de manera generalizada el cierre de todo un sector, como es el ocio nocturno. La cuestión es relevante porque nos permite conectar la posibilidad que asiste al poder autonómico para limitar la libertad de empresa con otras cuestiones abordadas en este trabajo: (1) la posibilidad de adoptar medidas limitativas de este cariz bajo la figura de la legislación de urgencia, (2) el parámetro empleado por el TC para enjuiciar la licitud de los límites establecidos a la libertad de empresa por el legislador y (3) la posibilidad de que el Derecho de la normalidad prevea el cierre, generalizado e indiscriminado, de todo un sector económico.

En cuanto a la legislación de urgencia se refiere, se debe partir de que el Decreto-Ley 7/2020, de 19 de octubre -que dio lugar a la Ley 3/2020- también contemplaba el cierre del ocio nocturno. Por otro lado, como ya se ha apuntado, a la hora de examinar si una regulación puede ser acometida 
legislador de urgencia, el TC viene entendiendo que, por afectar ${ }^{35}$, debe entenderse la regulación integral de un derecho o aquella que incida en aspectos sustanciales del mismo (STC 111/1983, de 2 de diciembre). Y entre estos aspectos sustanciales se encuentra el derecho a iniciar una actividad empresarial y, en lo que aquí interesa, a sostenerla en el tiempo (STC 83/1984, de 24 de junio). Razón por la cual, es probable que la decisión de regular el cierre generalizado de un sector es una materia vedada al decreto-ley. La tramitación como ley, por el procedimiento de urgencia, del Decreto-Ley aragonés 7/2020, de 19 de octubre, subsanó a priori este posible vicio.

Y se dice a priori porque existen algunas dudas sobre la capacidad que asiste al legislador ordinario para acordar una decisión de este calado. Es indudable que el legislador persigue un fin legítimo, que no es otro que la preservación de la salud, y el TC ha venido recurriendo exclusivamente al test de idoneidad para enjuiciar la licitud de las medidas restrictivas de derechos acordadas por el legislador. Sin embargo, este es el momento de incorporar al análisis que, recientemente, el TC ha modificado su jurisprudencia sobre la libertad de empresa en un extremo que tiene relevancia ahora.

Como ha señalado Cidoncha Martín ${ }^{36}$, tras la STC 89/2017, de 4 de julio, el TC ha comenzado a considerar que una medida limitativa del derecho a la libertad de empresa es constitucional si esta no supone un impedimento práctico para su ejercicio (igualmente, STC 111/2017, de 5 de octubre). Es cierto que, con este planteamiento, el TC se aproxima a una concepción absolutista de los derechos fundamentales, y tal concepción había sido desechada por el propio Tribunal en una consolidada jurisprudencia que va más allá del derecho a la libertad de empresa. Sin embargo, de mantenerse esta línea argumentativa, queda puesta en entredicho la constitucionalidad de una decisión del legislador acordando el cierre de un sector.

En el fondo, un razonamiento en estos términos, nos aproxima a concluir que, en nuestro sistema, las suspensiones generalizadas e indiscriminadas de derechos fundamentales solo caben en el marco del Derecho Constitucional de excepción, cuando estén debidamente justificadas por los principios de

\footnotetext{
${ }^{35}$ Pese a que la regulación estatutaria de la legislación de urgencia (art. 44 EAAr) no hace referencia a la afectación a la libertad de empresa, debe recordarse que los límites establecidos en el artículo 86 CE para los Reales Decretos-Leyes son aplicables también a los Decretos-Leyes autonómicos (STC 93/2015, de 14 de mayo).

${ }^{36}$ CIDONCHA MARTíN, A., "Coronavirus y libertad de empresa", op. cit. 
urgencia, necesidad y proporcionalidad. Tan solo si se atiende jurisprudencia constitucional que configura a la libertad de empresa como un derecho mutilado, podemos continuar afirmando la constitucionalidad de una medida que contempla el cierre in totum de un sector económico.

\section{III.INDEMNIZACIÓN POR LOS PERJUCIOS SUFRIDOS EN LA ESFERA PATRIMONIAL DE LOS PARTICULARES}

En este trabajo se ha tratado de diferenciar entre dos esferas jurídicas aparentemente desconectadas, la excepcionalidad (subepígrafes 1 y, en buena medida, 2 del apartado II) y la normalidad (subepígrafe 3). Sin embargo, ambos planos quedan unidos cuando se aborda una cuestión en absoluto menor: la posibilidad que tienen los particulares de reclamar al poder público una indemnización por las decisiones adoptadas por este.

Durante la normalidad, el marco normativo que permite a los particulares reclamar al poder público una indemnización es, por un lado, el contemplado en los artículos 32 y siguientes de la Ley 40/2015, de 1 de octubre, de Régimen Jurídico del Sector Publico (LRJSP). Dichos artículos, como es sabido, regulan el instituto de la responsabilidad patrimonial de las Administraciones Públicas, en desarrollo de lo previsto en el artículo $106 \mathrm{CE}$, y tienen carácter básico con base en el artículo 149.1. 18 $\mathrm{CE}$. Por otro lado, cuando la actuación administrativa que provoca una lesión patrimonial tiene naturaleza expropiatoria, el particular tiene derecho a percibir un justiprecio que compense la lesión sufrida en su derecho (art. 33.3 CE y, en el plano competencial, art. 149.1. 18으 $\mathrm{CE}$, que atribuye al Estado la competencia legislativa sobre este particular).

En la excepción, el legislador orgánico encargado de desarrollar el artículo 116 CE contempló que, quiénes como consecuencia de la aplicación de los actos y disposiciones adoptados bajo dicho régimen jurídico, sufran daños o perjuicios por actos que no les sean imputables, tendrán derecho a ser indemnizados de acuerdo con lo dispuesto en las leyes (de la normalidad). Así lo establece el artículo 3 LOAES. Y, de este modo, como se anticipaba, quedó tendido un puente entre la orilla de la normalidad y la de la excepción. Durante la excepción, los particulares tienen derecho a ser resarcidos por los perjuicios que sufran en su esfera patrimonial en los mismos términos que en la 
normalidad. A saber, a través de dos instituciones: la responsabilidad patrimonial y la expropiación.

\section{Un camino difícil de transitar: la posible responsabilidad patrimonial}

En lo que respecta a la responsabilidad patrimonial, debemos comenzar señalando que el artículo 32 LRJSP contempla realmente dos institutos diferentes, en función de si la lesión irrogada en la esfera patrimonial de los particulares fue provocada por el poder ejecutivo o por el poder legislativo. En este último supuesto lo preciso es hablar de responsabilidad del Estado-legislador.

Precisamente será este último supuesto el que nos merezca un mayor interés, atendiendo a que, según se ha visto hasta aquí, de haberse irrogado algún daño a determinados particulares, dicho perjuicio sería consecuencia -en la mayoría de las ocasiones- de la aplicación de actos legislativos de naturaleza no expropiatoria. Pues, tal y como se viene defendiendo en este trabajo, buena parte de las medidas adoptadas por los poderes públicos durante estos meses -en un contexto de emergencia no reglada-, no han supuesto una expropiación, sino que han constituido una limitación, intensísima en algunas ocasiones, del derecho fundamental a la libertad de empresa (vid. II.1) ${ }^{37}$.

Entre ellas destacan, muy especialmente, al artículo 10 del Real Decreto 463/2020, que como sabemos acordó el cierre del comercio minorista no esencial durante el estado de alarma declarado en marzo (vid. II.1). Pero también cabe incluir aquí otras previsiones normativas, como las contempladas en la antedicha Ley aragonesa 3/2020 que, en un contexto de crisis sanitaria, permitía adoptar medidas (reducción de aforos, limitación de horarios de apertura, etc...) con un impacto incuestionable en la cuenta de resultados de los negocios afectados (vid. II.3.B). Además, junto a estas decisiones, el legislador -normalmente el legislador de urgencia- ha adoptado otras decisiones que también han tenido un impacto económico incuestionable. Aquí cabe incluir, por ejemplo, las medidas ya aludidas previstas en los Reales Decretos-Leyes 8/2020, de 17 de marzo (imposibilidad del corte de suministro

${ }^{37}$ En contra, J. M. ASPAS Y ASPAS, quien ha defendido la naturaleza expropiatoria de estas decisiones. Cfr. "Víricas expropiaciones sin indemnización", Heraldo de Aragón, 12 de noviembre de 2020. 
de insumos) o 35/2020, de 22 de diciembre (reducción de los alquileres de inmuebles no destinados a vivienda).

Para que la responsabilidad patrimonial del Estado-legislador sea efectiva, es necesario que concurran una de las tres circunstancias contempladas en el artículo 32 LRJSP (apartados 3 y 4), y de las que aquí solo nos interesan dos ${ }^{38}$. En primer lugar, para que el derecho indemnizatorio nazca, es necesario que los actos legislativos que provoquen la lesión contemplen expresamente el derecho del particular a ser indemnizado. Por otro lado, también es posible que el derecho indemnizatorio sea reconocido cuando los daños deriven de la aplicación de una norma con rango de ley declarada inconstitucional siempre que el particular haya obtenido, en cualquier instancia, sentencia firme desestimatoria de un recurso contra la actuación administrativa que ocasionó el daño y, además, en dicha instancia hubiera alegado la inconstitucionalidad posteriormente declarada.

Ninguna de las disposiciones antedichas contempla expresamente la posibilidad de que los particulares sean indemnizados por los perjuicios que su aplicación les irrogue. Y, por ello, la única posibilidad de que el instituto de la responsabilidad del Estado-legislador sea virtualmente efectiva pasa por la declaración de inconstitucionalidad de las normas con rango de ley a las que se acaba de hacer referencia: bien sea como consecuencia de la resolución de un recurso de inconstitucionalidad ${ }^{39}$, o de una cuestión. En todo caso, con base en lo dispuesto en el artículo 32 LRJSP, es imprescindible que el particular haya recurrido la actuación administrativa que ocasionó el daño y que, en dicho pleito, haya alegado la inconstitucionalidad de la norma con rango de ley.

El problema que se plantea es que, la mayor parte de las disposiciones aludidas, no requieren de un acto administrativo de naturaleza aplicativa para desplegar efectos. De manera que, aparentemente, el particular solo puede articular un recurso si, previo incumplimiento de la norma con rango de ley, ha sido sancionado por el poder público y dicha sanción es recurrida. Desde

\footnotetext{
${ }^{38}$ La tercera está diseñada para exigir responsabilidad patrimonial al Estado por aplicación de una norma contraria al Derecho de la Unión Europea. Sobre este particular, y también sobre la cuestión que nos ocupa ahora, cfr. GONZALEZ ALONSO, A. "La responsabilidad del Estado legislador por vulnerar el Derecho Europeo o la Constitución", Revista Española de Derecho Constitucional, núm. 36, 2016, pp. 381-429.

${ }^{39}$ Recuérdese que los diputados del Grupo Parlamentario VOX en el Congreso de los Diputados interpusieron el 28 de abril de 2020 un recurso de inconstitucionalidad contra, entre otros, el artículo 10 RD 463/2020, que no ha sido resuelto en enero de 2021, momento de ser entregado este trabajo.
} 
luego, en los últimos meses no nos hemos encontrado con un incumplimiento ni generalizado, ni prácticamente ocasional, de las normas legales limitadoras de la actividad económica. Y si ello no ha sido así es, muy posiblemente, porque la inconstitucionalidad de estas normas es difícilmente sostenible desde una perspectiva jurídica, tal y como se ha tratado de evidenciar en el anterior apartado.

Sin embargo, las dificultades con las que se encuentran los particulares para ser indemnizados con base en el instituto de la responsabilidad del Estado-legislador, no solo vienen dadas porque la constitucionalidad de las normas aludidas parece difícilmente cuestionable. No podemos olvidar, además, que incluso en el mejor escenario para el particular -a saber, que el TC termine declarando la inconstitucionalidad de la norma que irroga el dañoel nacimiento del derecho indemnizatorio continúa siendo altamente improbable. En efecto, es frecuente que el TC, en aquellos supuestos en los la declaración de inconstitucionalidad puede provocar una avalancha de reclamaciones patrimoniales -y no cabe duda de que este sería un supuesto tal-, limite en el tiempo la eficacia de su fallo para evitar comprometer la sostenibilidad financiera del Estado (por todas, el leading case en la materia: STC 45/1989, de 20 de febrero).

\section{La expropiación como instrumento para intervenir empresas y requisar bienes}

De manera diferenciada deben ser tratadas las requisas temporales de bienes y la puesta a disposición del sector público de determinados centros privados -muy especialmente clínicas-.

En estos casos, como apunta Álvarez García, nos encontramos ante una privación del derecho a la propiedad privada en aras del interés general y, en consecuencia, el régimen jurídico que procede aplicar es el de la expropiación. En concreto, el artículo 120 de la Ley de Expropiación Forzosa ${ }^{40}$ que permite, en una coyuntura epidémica, la inmediata requisa de bienes o derechos particulares, demorando para un momento ulterior el abono del justiprecio.

40 ÁLVAREZ GARCÍA, V., "El Coronavirus (Covid-19): respuestas jurídicas frente a una situación de emergencia sanitaria", El Cronista del Estado Social y Democrático de Derecho, núms. 86-87, 2020, p. 18. 
En todo caso, también debe añadirse que el quantum de dicha indemnización debería cubrir, exclusivamente, los costes en los que incurrió un centro privado por prestar servicio, dejando a un lado el ánimo de lucro que, por definición, rige la actuación empresarial. Tan solo diluyendo el ánimo de lucro propio de la gestión privada se pueden repartir de forma equilibrada los costes derivados de una situación de emergencia. $Y$, en este sentido, no puede olvidarse que la Resolución de 12 de noviembre de 2020, de la Consellera de Sanidad Universal y Salud Pública, a la que ya se ha hecho referencia, contemplaba el abono de los servicios prestados a precio de coste, al remitirse en este aspecto a la Ley valenciana de tasas (cubriendo una tasa, por definición, el coste del servicio). Razón por la cual, es probable que tengan un recorrido discreto las acciones judiciales ejercitadas, al menos, contra esta resolución del Gobierno valenciano.

Puede resultar llamativo que una limitación intensísima del derecho a la libertad de empresa, como la suspensión temporal de la actividad, no sea indemnizable; mientras que otra más liviana -la intervención o la requisa de bienes- sí que lo sea. El perjuicio irrogado a un empresario al que se le impone un cierre temporal del negocio, es superior al sufrido por otro que ve su empresa "simplemente" intervenida. En la intervención, aunque sea bajo dirección pública, la empresa continúa en funcionamiento. Y aunque la gestión pública del negocio intervenido no tiene que regirse por una lógica de mercado, tratando de maximizar el beneficio, en estos supuestos, al mantenerse la actividad, se ven minimizadas las pérdidas. El cierre, por el contrario, avoca al empresario a soportar irremediablemente los costes fijos sin facturar ningún ingreso.

Esta paradoja ha sido resuelta por el profesor Doménech ${ }^{41}$, quien ha estudiado las diferencias entre una expropiación y una delimitación de la propiedad no indemnizable. En opinión de Doménech Pascual, para determinar si nos encontramos ante una u otra se debe establecer si "el ejercicio del derecho que resulta sacrificado por la Administración es intolerablemente peligroso o nocivo para la sociedad 0 , por el contrario, se trata de una actividad socialmente deseable". En el primer caso, estaríamos ante una limitación de un derecho no indemnizable -v. gr. art. 10 RD 463/2020-. En el segundo supuesto, por el

${ }^{41}$ DOMÉNECH PASCUAL, G., "Responsabilidad patrimonial del Estado por la gestión de la crisis del Covid-19", El Cronista del Estado Social y Democrático de Derecho, núms. 86-87, 2020, p. 109. 
contrario, la indemnización sería pertinente, para fomentar que los agentes económicos continúen realizando actividades socialmente valiosas -como la prestación de servicios sanitarios, asistencia a mayores, producción de mascarillas, etc...-.

Como conclusión a este epígrafe, pero también al presente capítulo, cabe señalar que, si bien parece improbable el reconocimiento en vía judicial, en la mayoría de las ocasiones, de una indemnización que compense los perjuicios económicos padecidos; nada impide a los diferentes niveles de poder, y así lo han hecho, articular un abanico de mecanismos extraordinarios de financiación para tratar de paliar los estragos económicos derivados de la crisis sanitaria. Y repartir éstos entre todos los contribuyentes. La magnitud de estos estímulos económicos ha podido ser más o menos discreta, pero un juicio en estos términos solo puede realizarse desde una perspectiva política que aquí no corresponde. En este momento tan solo procede recordar que el principio de riesgo y ventura es consustancial a la actividad económica, teniendo el empresariado el deber jurídico de soportar las decisiones adoptadas por el legislador dentro del marco constitucional. Y si esta reflexión es válida para cualquier momento, más debería serlo en una situación como la vivida en los meses recientes, caracterizada por una gravedad que ha alcanzado una envergadura inimaginable. 